\title{
LA INTERVENCIÓN MILITAR AUTORIZADA DE LAS NACIONES UNIDAS EN LIBIA: ¿UN PRECEDENTE DE LA «RESPONSABILLDAD DE PROTEGER»?
}

Un military authorized intervention in Libia:
a precedent of the responsibility to protect?

María Cecilia Añaños Meza*

Sumario

En febrero de 2011 surgió el conflicto libio que generó una intervención internacional intensiva y amplia de las Naciones Unidas, que impuso sanciones y autorizó el empleo de la fuerza contra el régimen de gobierno libio, en aras de la «responsabilidad de proteger». El presente trabajo examinará, desde la perspectiva del derecho internacional público, el mecanismo de sanciones de las Naciones Unidas, sus características y el concepto de la «responsabilidad de proteger» y su papel dentro del sistema de sanciones del Consejo de Seguridad y la cuestión de la conformidad de las sanciones con la Carta y el derecho internacional.

Palabras Clave: conflicto libio, seguridad colectiva, sanciones, Consejo de Seguridad, responsabilidad de proteger, Capítulo VII de la Carta de las Naciones Unidas

Académica y traductora. ceciliaan@web.de

Recibido el 22 de junio de 2012; aceptado el 20 de febrero de 2013. 


\section{Abstract}

The Libyan conflict that broke out in February 2011 originated a farreaching and severe intervention with the participation of the United Nations, which imposed sanctions and authorized the use of force against the Libyan government invoking the «responsibility to protect». The following paper examines, from the perspective of public international law, the sanctions mechanism applied by United Nations, its characteristics, the concept of the «responsibility to protect» and its role in the sanctions regime of the Security Council, and the question of the regime's consistency with the UN Charter and public international law.

KeYwORDS: Libyan conflict, collective security, sanctions, Security Council, responsibility to protect, Chaper VII of the Unitged Nations Charter 
M. Cecilia AÑaños • La intervención militar autorizada...

\section{INTRODUCCIÓN}

Seis años después de aprobado por la Asamblea General de las Naciones Unidas resurge el concepto de la «responsabilidad de proteger» en el conflicto libio desatado a comienzos de 2011 como justificación para la aplicación de sanciones por las Naciones Unidas que sin duda demostraron haber sido implementadas de la manera más eficiente de que se tenga memoria en la organización.. Además de su eficacia cabe destacar el amplio consenso logrado entre los miembros de las $\mathrm{Na}$ ciones Unidas para su aplicación, que indica el comienzo de un nuevo orden jerárquico universal en el campo de las sanciones internacionales bajo la égida conceptual de la «responsabilidad de proteger». Pero este régimen de intervención previsto para casos de crímenes graves cometidos por los gobiernos contra su propia población civil no se ha acompañado de un debate suficiente sobre la necesidad de su existencia, ni de una maduración del concepto que permita disponer de criterios adecuados sobre sus límites, ni de una garantía institucional de supervisión y control por instancias internacionales neutrales, lo que hace su consagración como norma de derecho internacional resulte moral y jurídicamente problemática, por no mencionar el carácter altamente controvertido que encierra el núcleo esencial del propio concepto, esto es, la intervención humanitaria.

Teniendo presente lo anterior, el presente trabajo no se dedicará a re- batir en un plano jurídico o moral el concepto de la «responsabilidad de proteger» sino que se limitará a analizar la aplicación de la «responsabilidad de proteger» en el conflicto libio desde la perspectiva del derecho internacional público, incluyendo la determinación del carácter de las sanciones aplicadas por las Naciones Unidas, el papel que desempeña el concepto de la «responsabilidad de proteger» dentro del mecanismo sancionador del Consejo de Seguridad y la cuestión de su conformidad con la Carta y el derecho internacional, no sin antes dar una breve relación de los hechos con datos relevantes para el examen del conflicto.

\section{LOS HECHOS}

Dentro de la euforia de las llamadas « revoluciones pacíficas» $\mathrm{O}$ « primavera árabe ", surge el conflicto libio con una ola de manifestaciones masivas que culminaron rápidamente en una rebelión armada que en pocos días adquirió el carácter de guerra civil, total y sangrienta. La crisis interna empezó con protestas violentas un martes 15 de febrero de 2011 en Bengasi ${ }^{1}$. En los días posteriores aumentó la escalada de violencia y también la respuesta del gobierno, lo

1 Protesta de unos 2000 manifestantes, número no representativo de la población libia. Sobre su carácter violento: „Reportan violentas manifestaciones en Libia «, BBC Mundo, 16.02.2011 http://www.bbc. co.uk/mundo/ultimas_noti cias/2011/02/110215_ultnot_libia_manifestaciones_jrg.shtml (1.2.2012). 
que llevó al choque entre manifestantes y las fuerzas policiales; situación que fue sustancialmente agravada por la presencia de «bandas armadas» que disparaban arbitrariamente causando centenares de muertos y heridos ${ }^{2}$. Al mismo tiempo se produjo una rebelión armada en Bengasi, que en pocos días se extendió a todo el este del país. El 22 de febrero Gadafi perdió el control de esta y otras ciudades de esta parte del país, dándose las condiciones objetivas de un conflicto armado $^{3}$. El 27 de febrero, los

2 Las cifras de muertos y heridos se elevó a las decenas a pocos días del estallido de la crisis, sin conocerse claramente, quiénes fueron las mismas ni en qué circunstancias cayeron víctimas. A raíz de estos sucesos no claros, el gobierno de Gadafi fue acusado de incurrir en violaciones serias y sistemáticas de derechos humanos: «Gadafi reprime la revuelta con morteros y ametralladoras», El Pais 20.02.2011: http:/www.elpais.com/articulo/internacional/Gadafi/reprime/revuelta/morteros/ametralladoras/elpepiint/20110220elpepiint_3/ Tes (1.2.2012); «Al menos 250 muertos por los bombardeos en Trípoli según $\mathrm{Al}$ Jazeera, Expansión.com 21.02.2011 http://www.expansion.com/2011/02/21/ economia/politica/1298313621.html?a=1 efa 6c8396d5673f 83331 bcd 18 a 8 ba 42 $\& t=1325195934$ (5.2.2012).

3 «Gadafi lucha a la desesperada por mantener el control del oeste de Libia, El País 23.02.2011 http://www.elpais.com/articulo/internacional/Gadafi/lucha/desespera$\mathrm{da} / \mathrm{mantener/control/oeste/Libia/}$ elpepuint/20110223elpepuint_4/Tes (10.2.2012); «milicias antigubernamentales expanden su control y se acercan a Trípoli, El Mundo 24.02.2011 http:// www.elmundo.es/elmundo/2011/02/24/ internacional/1298553552.html (10.2.2012). rebeldes, teniendo en su poder el este del país y bajo su control los yacimientos petrolíferos libios más importantes fundaron oficialmente el Consejo $\mathrm{Na}$ cional de Transición (CNT) en Bengasi, gobierno de facto paralelo, formado por «militares desertores y voluntarios civiles, académicos, líderes de tribus, diplomáticos y políticos desertores del gobierno", como único cuerpo legítimo de representación del pueblo y del Estado libios ${ }^{4}$. Paralelamente, la comunidad internacional condenaba moralmente el régimen de gobierno de Gadafi.

\section{LA REACCIÓN DE LA "COMUNIDAD INTERNACIONAL»}

El 22 de febrero la Liga Árabe suspendió a Libia de su participación en la Organización, y al cabo de horas lo hicieron también la Organización de la Conferencia Islámica y la Unión Africana $^{5}$. El mismo día -22 de febrero- la Alta Comisionada de Derechos

4 Primer país en reconocer al CNT fue Francia, el 10 de marzo, seguido de Qatar, el 28 de marzo; ambos seguidos a la vez por los demás países, incluso China y Rusia, y organizaciones internacionales. La ONU lo hace oficalmente el 16 de septiembre y la UA, 20 de septiembre.

5 «OIC General Secretariat Condemns Strongly the Excessive Use of Force against Civilians in the Libyan Jamahiriya", Organisation of Islamic Conference, 22.02.2011, http://www.oic-oci.org/ topic_detail.asp?t_id=4947\&x_key (27.2.2012); "African Union slams violence in Libya», Press TV, 23.02.2011 http://www.presstv.ir/detail/166751.html (27.2.2012). 
Humanos de las naciones Unidas hizo pública su condena al gobierno libio por «el uso de la fuerza», llegando a calificar la situación de "crimen contra la humanidad $»^{6}$. Al día siguiente, y respaldando las declaraciones de la Alta Comisionada, el Secretario General, Ban Ki-moon, invocó la doctrina de la «responsabilidad de proteger» para recalcar la responsabilidad del gobierno libio por los ataques a su población 7 .

Con estos antecedentes, el 26 de febrero el Consejo de Seguridad impuso sanciones no militares a Libia (Res. 1970). Al cabo de cuatro días, la Asamblea General expulsó a Libia del Consejo de Derechos Humanos ${ }^{8}$. En menos de un mes, al 17 de marzo, el Consejo de Seguridad amplió e intensificó sus sanciones (Res. 1973) imponiendo sanciones militares. Consiguientemente, el 18 de marzo, una "coalición internacional», liderada por Francia y de la que formaron partge Estados Unidos y el Reino Unido dio comienzo a la ope-

6 «Pillay calls for international inquiry into Libyan violence and justice for victims", UN-HR, OHCHR, comunicado del 22 de febrero 2011 http://www.ohchr.org/en/ NewsEvents/Pages/News Search. aspx? CID=LY (2.2.2012).

7 «UN Secretary General Ban Ki-moon condemns Libya violence» BBC News 23.02.2011 http://www.bbc.co.uk/news/ world-middle-east-12561784 (1.3.2012).

8 UN Doc. A/RES/65/265, 3.03.2011, adoptada el 1 de marzo por consenso de 192 países, motivada por el Consejo de Derechos Humanos, UN Doc. A/HRC/S-15/2 del 25 de febrero, bajo la convicción de que el gobierno de Gadafi ha cometido violaciones serias y sistemáticas de derechos humanos. ración 'Odisea al amanecer' contra las fuerzas de Gadafi', atacándolas por aire (Francia) y por mar (Estados Unidos y el Reino Unido) con el objetivo de destruir sus defensas aéreas, depósitos de suministro y tropas terrestres. A partir del 23 de marzo la OTAN asumió el control del embargo de armas y de la zona de prohibición de vuelos en Libia, extendiendo el 27 de marzo su mandato para «implementar todos los aspectos de la resolución 1973 del Consejo de Seguridad de la ONU », asumiendo el control de las operaciones militares sobre el espacio aéreo y naval libio, mediante la operación «Protector Unificado» a fin de "proteger a los civiles y áreas pobladas por civiles bajo el ataque y amenaza del régimen de Gadafi».

Entretanto, en plena contienda militar internacional hubo intentos repetidos de mediación por parte de la UA y concesiones importantes de Gada$\mathrm{fi}^{10}$. En Londres se creó un "Grupo de Contacto» o «Alianza Internacional»

9 Otros países participantes en esta coalición fueron España, Italia Canadá, Dinamarca, Bélgica, Norruega, Qatar, Emiratos Árabes Unidos y Turquía.

10 A mediados de marzo y en abril, la Unión Africana (UA) intenta mediar y propone una «hoja de ruta» que preveía el cese inmediato de las hostilidades, un corredor para la ayuda humanitaria y el diálogo inmediato entre el gobierno y el CNT hacia una transición democrática, a esto vid. « Los rebeldes libios rechazan el 'cese de hostilidades' aceptado por Gadafi », El Mundo, 11.4.2011 http:// www.elmundo.es/elmundo/2011/04/10/ internacional/ 1302470647 .htm l (14.3.2012). También en mayo se registran intentos de mediación rusa. 
que a un alto nivel político consolidó, mediante ayuda financiera, la suerte política del país bajo el nuevo gobierno rebelde de Bengasi. En el mes de junio se abrió un proceso penal con órdenes de arresto contra Gadafi y allegados del régimen ${ }^{11}$. El 22 de agosto los rebeldes entraron a Trípoli, ocuparon el Palacio de Gobierno, capturaron a tres hijos de Gadafi y ofrecieron una recompensa por su captura. Dos meses después (21 de octubre), al huir de Sirte, Gadafi es interceptado y emboscado mediante bombardeos desde aire y tierra, hasta que fue capturado y ejecutado ${ }^{12}$. Una vez celebrada la caída del régimen de Gadafi, el Consejo de Seguridad de las naciones Unidas resolvió poner fin a la autorización para ell uso de la fuerza a partir del 31 de octubre, concluyendo en la misma fecha la operación «Protector unificado» de la OTAN ${ }^{13}$. El tema de Libia desaparece rápidamente de los titulares de la prensa y de la agenda internacionales.

11 El 1 de junio una Comisión Investigadora del Consejo de Derechos Humanos, a cargo de Cherif Bassiouni, confirma la comisión de crímenes de lesa humanidad y crímenes de guerra del gobierno libio en forma de detenciones arbitrarias, desapariciones forzadas, ataques indiscriminados a la población civil, etc.; vid. Informe UN Doc. A/HRC/17/44 del 1.6.2011 y UN Doc. A/ HRC/19/68 de marzo de 2012.

12 Wie die NATO Gaddafi jagte «, Der Spiegel, 21.10.2011, http://www.spiegel.de/politik/ ausland/0,1518,793179,00.html (1.3.2012).

13 UN Doc. S/RES/2017, 27 de octubre de 2011.
II. LA LEGALIDAD DE LAS

\section{SANCIONES INTERNACIONALES CONTRA LIBIA}

Las sanciones internacionales contra Libia se realizaron de acuerdo con el sistema de las naciones Unidas sobre la base de dos resoluciones del Consejo de Seguridad: la Res. 1970 del 26 de febrero que imponía sanciones no militares, y la Res. 1973 del 17 de marzo que autorizaba además sanciones militares. La legalidad formal de las mismas parece ser indiscutible por estar fundamentadas en el cap. VII de la Carta dentro de las atribuciones del Consejo de Seguridad de velar por la paz y la seguridad internacionales y con el respaldo de la Asamblea General y órganos de derechos humanos de las Naciones Unidas, y a juzgar por la falta de protestas, con el aval cuasiuniversal de los Estados miembros. Sin embargo, incongruencias notables en el desarrollo de los hechos y en el contenido de los documentos pertinentes obligan a revisar la base jurídica de las sanciones, para alo cual se hará hincapié en las sanciones que permitieron el uso de la fuerza, el ius ad bellum, por consituir el extremo más severo del régimen de sanciones impuesto a Libia. Por la falta de espacio se pasan por alto el estudio detenido de las sanciones no militares con su implicación penal internacional, y los problemas del ius in bello. 
M. CeCilia AÑAÑos • La intervención militar autorizada...

\section{Las sanciones no militares de las Naciones Unidas}

La resolución $1970^{14}$, que fue aprobada por voto unánime de los miembros del Consejo de Seguridad, impuso amplias y severas sanciones con arreglo al Capítulo VII de la Carta, las que desde la perspectiva de su destinatario pueden clasificarse en dos categorías. Las primeras, que forman casi exclusivamente el contenido de este documento, corresponden a sanciones individuales o "targeted sanctions» ${ }^{15}$, de carácter punitivo y dirigidas directamente contra el régimen de gobierno libio. Dentro de ellas cabe mencionar la imposición a este de ciertas obligaciones directas de protección del pueblo libio y medidas humanitarias, el envío del caso a la Corte Penal Internacional, la prohibición de salida del país y el congelamiento de bienes y activos financieros de líderes y familiares del gobierno que figuraban en una lista, ello basándose en que las autoridades libias eran responsables

14 UN Doc. S/RES/1970, 26 de febrero de 2011.

15 Sobre las sanciones individuales vid. Willis, G.L., «Security Council Targeted Sancions, Due Process and the 1267 Ombusdperson", Georgetown Journal of International Law, Vol. 42, 2011, 673-745 ; WolfZimper, G., Zielgerichtete Sanktionen des Sicherheitsrates der VN und effektiver Rechtsschutz, Univ. Diss., Lang, Frankfurt a.M. 2008, p. 15ss., Fassbender, B., Trageted Sanctions and Due Process, HUBerlin 2006, http://www.un.org/law/ counsel/Fas s bender_study.pdf (15.3..2012); Birkhäuser, N., Sanktionen des Sicherheitsrats der Vereinten Nationen gegen Individuen, Peter Lang, Bern 2007. de una " grave y sistemática violación de derechos humanos, incluida la represión de manifestantes pacíficos ", de "la incitación a la hostilidad y la violencia contra la población civil » y de « ataques generalizados y sistemáticos contra la población civil ", que " pueden constituir crímenes de lesa humanidad» ${ }^{16}$. La segunda categoría de sanciones que también figura en el documento, aunque no con el peso de las anteriores, es de carácter general y se dirigen contra el Estado libio como tal, y consistían en un embargo total de armas. El objetivo de todas estas sanciones no militares sería poner fin a la violencia, obtener el respeto de los derechos humanos y proteger a la población civil.

Como se desprende de los motivos expuestos, esas medidas eran en primer lugar una respuesta a la existencia de una «violación grave y sistemática de derechos humanos», lo que en relación con una crisis humanitaria constituye desde hace tiempo factor suficiente para que el Consejo de seguridad ordene sanciones no militares y/o militares. ${ }^{17}$. Sin embargo, en este caso incluyen un factor novedoso para el régimen de sanciones de las Naciones

16 UN Doc. S/RES/1970, 26 de febrero de 2011.

17 Valga citar como ejemplo las sanciones contra Irak (Res. 688/1991), por la violación de derechos humanos con el resultado de la corriente de refugiados en el Norte de Irak, y contra Yugoslavia (Res. 787/1992 y 820/1993), por violaciones graves del derecho humanitario y el costo de vidas y daños materiales. 
Unidas consistente en los actos de «incitación a la hostilidad y la violencia contra la población civil» y los "ataques generalizados y sistemáticos contra la población civil», que forman parte de la doctrina de la «responsabilidad de proteger», mencionada claramente en la parte dispositiva del documento cuando recuerda "la responsabilidad de las autoridades libias de proteger a su población» ${ }^{18}$. Con ello, el Consejo de Seguridad asocia por primera vez la «violación grave y sistemática de los derechos humanos" con la violación de la «responsabilidad de proteger» para subsumirlos en el supuesto general de "amenaza a la paz» del Art. 39 de la Carta de la ONU ${ }^{19}$, y dar paso así, a las sanciones previstas en el Art. 41 de la Carta.

Estas sanciones, que no autorizan el uso de la fuerza, constituyen de por sí medidas tan severas que no solo afectan la situación económica, política, social y moral de todo el país, sino también los derechos humanos fundamentales de sus destinatarios, como el derecho a la libertad y a la propiedad, el derecho a la protección jurídica, la garantía de presunción de inocencia, el derecho a un debido proceso, además de despojar de facto otros derechos como el relativo al reconocimiento del gobierno e inmunidades de su presidente y derechos deri-

18 UN Doc. S/RES/1970, 26 de febrero de 2011.

19 Aunque no hace mención expresa a la fórmula de "amenaza a la paz», ésta está implícita o sobrentendida al referirse al cap. VII de la Carta. vados, junto con el de legítima defensa. La gravedad de las sanciones obliga a examinar su coherencia legal material , lo que se hará al tratar las sanciones militares, ya que ambas forman parte de un sistema cerrado y unitario y el trabajo se limita a centrar la atención en las últimas.

Mas también se requiere una revisión de la legalidad del proceso de decisión, que rápidamente revela manifiestas irregularidades en las consultas realizadas para aprobar la primera resolución. En efecto, esta fue aprobada en condiciones muy discutibles puesto que no se dio a las autoridades libias, acusadas de gravísimos de crímenes internacionales, la oportunidad de ser escuchadas para presentar su versión de los hechos y tomar posición o defensa de tales cargos, con lo cual el Consejo de Seguridad entró en conflicto con el Art. 32 de la Carta que establece que el Miembro parte en una controversia sea «invitado a participar» en las discusiones sobre ella ${ }^{20}$. Esta norma tiene carácter obligatorio para el Consejo de Seguridad, y su violación habilita para

20 Problema que se remonta a las primeras sanciones (contra Rodesia en 1967), en las que se negó este derecho bajo el argumento de que no se trataba de un Estado. Sobre el Art. 32 como un derecho de participación vid. Dolzer, R., en Simma, B. (Ed.), The Charter of the United Nations, Oxford University Press, 2002, p. 580ss. Sobre este principio en conexión con las sanciones de Rodesia vid. Kuyper, P.J., The Implementation of International Sanctions, Univ. Diss. Amsterdam 1978, p.8s. 
M. CeCilia AÑaños • La intervención militar autorizada...

declarar la ilicitud de las sanciones ${ }^{21}$. El Art. 32 es pues, una garantía procesal tenue y expresión mínima del principio audi et alteram partem, o derecho a ser oído que más que regla del debido proceso es un principio fundamental de justicia natural y equidad, existente sustancialmente en todo orden social y jurídico, cuando, guiados por un mínimo sentido de justicia se concede esta oportunidad a quien sea inculpada de una falta o delito, debido a que estará internalizado en nuestro espíritu moral humano. Se trata sobre todo de preservar esta garantía como derecho humano de los destinatarios, pero también de un derecho de todos los Estados Miembros de las Naciones Unidas de conocer e informarse sobre la posición del gobierno libio frente a los hechos ocurridos, sus descargos frente a las acusaciones y, de ser el caso, sus justificaciones. La negación de este derecho tiene entonces significativas consecuencias para los Miembros de la Organización porque importa la privación de una fuente importante de conocimiento e información sobre el conflicto libio.

Además de este conflicto con el Art. 32, cabe mencionar el hecho aún más problemático de que, en las reuniones y consultas, paraa votar las sanciones el Consejop de Seguridad aceptó a un embajador disidente y representante de los rebeldes, que no solo confirmó los cargos contra el gobierno libio sino que hizo lobby en favor de la adopción

21 En este sentido Dolzer, R., op,cit, (n.22), p. 579 . de medidas más duras contra su país ${ }^{22}$. La calidad de disidente y el hecho de que esta persona era representante de los insurrectos armados era de conocimiento general, presumiéndose con mayor razón que el Consejo de Seguridad conocía de esta situación. Sin embargo, lo trató en las consultas como representante de Libia e incluso le concedió el derecho de participar en ellas, con lo cual realizó un reconocimiento de facto de los rebeldes libios, no solamente como beligerantes o combatientes, sino sobre todo como representantes del pueblo y del Estado libios al inicio de la contienda armada, antes de que se constituyeran oficialmente como gobierno de facto y antes de existir las sanciones, a lo cual hay que sumar que los insurrectos no eran mencionados en ninguna parte del proyecto de resolución. Esta situación acarreaba automáticamente la anulación de hecho del reconocimiento del gobierno de Gadafi como representante de Libia por el Consejo de Seguridad y las Naciones Unidas, con su consiguiente deslegitimización internacional antes de que se impusieran sanciones, con lo cual la Organización se situaba prematuramente como parte interviniente en el conflicto armado al lado de los rebeldes libios. Este hecho lamentablemente no ha sido advertido -al menos oficialmente- por ningún miembro del Consejo de Seguridad ni de las Naciones Unidas.

22 6491a Sesion del Consejo de Seguridad de 26 de febrero de 2011, UN Doc. S/ PV.6491. 
Por último, cabe señalar que la trascendencia política de esta resolución radica en servir de precedente para la aplicación de la doctrina de la «responsabilidad de proteger» a futuros casos y allanar el camino para una resolución posterior aún más severa, que sí permitiría el uso de la fuerza.

\section{Las sanciones militares}

La resolución $1973^{23}$ intensifica y amplía las sanciones de la Res. 1970 con una serie de medidas no militares. Siguiendo su modelo, reitera las obligaciones impuestas, intensifica las sanciones individuales relativas a la congelación de activos y la restricción de los viajes, así como aquellas relacionadas con el embargo de armas, e impone además la prohibición del tránsito internacional de aeronaves libias. Sin embargo, el núcleo central y relevante de esta resolución es la imposición de sanciones militares que, de acuerdo con su contenido, consisten en una de carácter general y otra de carácter específico. La primera se encuentra en el apartado 4, que autoriza a los Estados miembros a que «adopten todas las medidas necesarias» para "proteger a los civiles y las zonas pobladas por civiles que estén bajo amenaza de ataque» en Libia. La segunda corresponde a los apartados 6 y 8 , en que se establece una zona de prohibición de todos los vuelos en el espacio aéreo libio "a fin de ayudar a proteger a los civiles» y autoriza

23 UN Doc. S/RES/1973, 17 de marzo de 2011. a los Estados miembros para «adoptar todas las medidas necesarias» para hacer cumplir tal prohibición. Los motivos aducidos consisten en primer lugar en el no acatamiento por «las autoridades libias» de las obligaciones impuestas en la resolución anterior y en el «deterioro de la situación». En segundo lugar se refiere a la "grave y sistemática violación de los derechos humanos", comprobable en detenciones arbitrarias, desapariciones forzadas, tortura y ejecuciones sumarias, sin nombrar directamente a los autores; seguidamente menciona los "ataques generalizados y sistemáticos contra la población civil» que "pueden constituir crimenes de lesa humanidad", tampoco mencionando directamente a los presuntos autores, lo que sí hace en apartados posteriores, cuando alude en forma directa a las fuerzas aéreas y navales libias como autores de los «ataques contra la población civil» y a las autoridades libias por los actos de violencia e intimidación contra los medios informativos, y a la utilización de mercenarios. De acuerdo con esta resolución, la autorización del uso de la fuerza tiene por objeto proteger a la población civil y a las zonas pobladas por civiles y, como objetivo secundario, facilitar el tránsito rápido y sin trabas de la asistencia humanitaria y resguardar la seguridad de su personal, entendiéndose que estas sanciones no están destinadas directamente a poner fin a la violencia sino que dentro de ella o con su ayuda proteger a la población civil y proporcionar la asistencia humanitaria debida. 
M. CeCilia AÑaños • La intervención militar autorizada...

El sustento legal formal de estas medidas es igualmente el Capitulo VII de la Carta que permite al Consejo de Seguridad imponer sanciones militares. Para ello, el Consejo consideró una vez más que la "grave y sistemática violación de derechos humanos» y los "ataques generalizados y sistemáticos contra la población civil» eran una amenaza a la paz de acuerdo con el Art. 39 de la Carta, siendo los «ataques generalizados y sistemáticos contra la población civil» el motivo predominante y central de las medidas, que a su vez es el supuesto central de la doctrina de la «responsabilidad de proteger», que se examinarás más de cerca a fin de conocer de qué manera ella forma la base del presente régimen sancionador.

\section{La «responsabilidad de proteger»}

Como se acaba de ver, el nuevo concepto de «responsabilidad de proteger» cumple una función fundamental en las sanciones impuestas a Libia en las dos resoluciones del Consejo de Seguridad y es la primera vez que se utiliza con ese nombre en relación con un mecanismo amplio de sanciones no militares y militares contra un Estado miembro de las naciones Unidas. En estas resoluciones la «responsabilidad de proteger» aparece como una norma moral que impone a los gobernantes libios el deber de proteger a su población civil y cuyo incumplimiento da lugar a la protección subsidiaria de la «comunidad internacional», representada en este caso por el Consejo de Seguridad. El papel que desempeña aquí el concepto consiste en ser el factor justificativo, no único pero principal, de todo el régimen sancionador y además, su factor agravante. De acuerdo con la practica, al Consejo de Seguridad le hubiera bastado basarse en la «violación sistemática y grave de los derechos humanos" para sellar la legalidad formal de las sanciones con arreglo al Capítulo VII. Sin embargo, agregó los "ataques generalizados y sistemáticos contra la población civil» agravando así la apreciación de la situación y trayendo consigo el elemento punible de las sanciones, junto con la condena o sanción moral internacional al mismo tiempo que se hacía oportuno estrenar el concepto de la «responsabilidad de proteger» en su faceta más dura.

La «responsabilidad de progeter» es el nombre artificial que se ha dado a la antigua doctrina de la guerra justa, que en su versión moderna se conoce como intervención humanitaria ${ }^{24}$. En el sistema de las naciones Unidas este concepto se asentó en dos cláusulas del Documento Final de la Cumbre Mundial de 2005 con el título de «derechos humanos e imperio de la ley» ${ }^{25}$, aunque su antecesora, la intervención humanitaria, ya era aplicada por la organización dentro de su sistema de sanciones y gestión de conflictos en casos de conflictos virulentos en deter-

24 A esto con más profundidad vid. Añaños Meza, M. C., La «Responsabilidad de proteger» y la intervención de la ONU en Libia, EAE 2012.

25 UN Doc. A/RES/60/1, 24 de octubre 2005. 
minados países y en conexión con crisis humanitarias y/o serias violaciones de los derechos humanos y del derecho humanitario ${ }^{26}$. En lo referente al uso colectivo de la fuerza, el Documento Final dice lo siguiente:

«En este contexto, estamos dispuestos a adoptar las medidas colectivas, de manera oportuna y decisiva, por medio del Consejo de Seguridad, de conformidad con la Carta, incluido su capítulo VII, en cada caso concreto [...], si los medios pacíficos resultan inadecuados y es evidente que las autoridades nacionales no protegen a su población del genocidio, los crímenes de guerra, la depuración étnica y los crímenes de lesa humanidad (párr. 139)27.

De este texto solo se puede extraer un deber moral de adoptar medidas co-

26 La ONU cuenta desde los años 90 con un buen historial de intervenciones humanitarias que venían acompañadas de medidas de protección a la población civil, como en los casos de Irak, Somalia, Yugoslavia, Ruanda, Haiti, Timor Este, etc., y últimamente en conflictos como los de Sierra Leona, Liberia, Costa de Marfil, Chad, República Central Africana, RDC y Sudán. Que la intervención humanitaria ya sea parte de la lex lata del sistema de la ONU es un argumento dificil de rebatir; a esto vid. Amnéus, D., Responsibility to Protect by Military Means, Stockholm University, Stockholm 2008, p.208. Pero en su forma unilateral sigue siendo su legalidad controvertida y categóricamente negada por la mayoría doctrinaria, respaldada por la Corte Internacional de Justicia en los casos Nicaragua y Armas Nucleares, a esto vid. Randelzhofer, A., "Use of Force», EPIL 4, Q-Z, 2000, p.1258.

27 UN Doc. A/RES/60/1, 24 de octubre 2005. lectivas, incluyendo el uso de la fuerza, sujetas a determinadas condiciones. La primera de ellas es la sujeción a las disposiciones de la Carta, mientras en un segundo orden se encuentran límites específicos, como el empleo previo de los medios pacíficos o último recurso y el de la «evidencia de no protección». El requisito de ser el último recurso exige que al menos se haya intentado recurrir previamente a los medios pacíficos disponibles previstos en los Art. 2(3) y 33 y Art. 2(4) de la Carta. Por su parte, el requisito de la «evidencia de no protección» requiere que exista certeza de la necesidad concreta de protección por parte de sus titulares y su no satisfacción por el gobierno en actos indubitables, exigencia que requeriría al menos una investigación breve e intensiva de los hechos por una instancia mediadora neutral e imparcial, que no se da en las condiciones dadas del sistema internacional. Ambos límites exigen a la vez que se cumpla con el requisito de que la medida se necesaria, lo que requiere que se busquen medios de protección alternativos menos agresivos o intensos pero igualmente adecuados, con lo cual se descartan las acciones preventivas o anticipadas, sea colectivas o unilaterales.

Pero el uso colectivo de la fuerza en virtud de la «responsabilidad de proteger» contiene también limitaciones conceptuales o intrínsecas que exigen que se haga un examen de su motivo correcto, el que se daría en las grandes pérdidas de vidas humanas y en la violación del «deber de protección»; su 
M. Cecilia AÑaños • La intervención militar autorizada...

intención correcta, que está dirigida a proteger o salvar vidas humanas dentro de la población civil; y el hecho de que el medio sea proporcional, esto es, solo se permite el empleo de medidas que conducen a este fin. Una acción militar en los casos en que no hay una población civil concreta que salvar, o que tiene propósitos políticos bien definidos como el cambio de régimen, o que ha empleado fuerza excesiva al incluir objetivos militares y estratégicos alejados del objetivo humanitario, como el entrenamiento, armamento y equipamiento de fuerzas rebeldes ${ }^{28}$, o el aplastamiento total de las fuerzas militares de la otra parte, quedan fuera del concepto de «responsabilidad de proteger» aceptado por los Estados, además de que, como se verá, son incompatibles con los propósitos y principios de la Carta. Estos casos sustraerían la autenticidad a toda intervención militar en nombre de la «responsabilidad de proteger» y la convertirían en ejemplo simulado o pretexto de esta. Con ello queda contestada de forma negativa la cuestión de si la «responsabilidad de proteger», como concepto aceptado por los Estados en general, permite acciones militares que tienden al cambio de régimen.

En el caso libio, los motivos correctos, consistentes en los "crímenes de lesa humanidad» y «ataques a la población civil» no pueden sostenerse ni mucho menos fueron evidentes al

28 «Military and Paramilitary Activities in and against Nicaragua", I.C.J. Reports 1986, p. 127, 134-5. momento de decidir sobre las pimeras sanciones, porque además de la ambigüedad y carencia de toda claridad sobre las circunstancias de su comisión, la existencia de protestas violentas difícilmente puede conciliarse con la aparición paralela y el avance rápido de la rebelión armada y la infiltración de grupos que no estaban bajo control del gobierno; aparte de que al aplicarse las primeras sanciones no había ninguna investigación provisional ni existían observadores independientes en el lugar. Los encargados de aplicar las sanciones militares tampoco tuvieron el objetivo o fin correcto, que debió ser el humanitario de "protección de la población civil», puesto que condujeron directamente al derrocamiento del régimen de gobierno libio. Tampoco se observaron los medios correctos o idóneos porque las operaciones militares se desviaron del objetivo concreto de protección a la población civil hacia objetivos militares de las fuerzas armadas fieles al gobierno libio y objetivos civiles de este. No se conoce acción puntual de resguardo de la población civil, ni de las vidas humanas salvadas por la «coalición internacional» o la OTAN en sus operaciones.

La insostenibilidad de los motivos, objetivos y medios correctos arriba examinados quitan toda autenticidad a esta intervención autorizada de las Naciones Unidas y la convierten en un ejemplo simulado o pretextado de «responsabilidad de proteger», pese a su indiscutible efectividad y aparente perfección, y pese a la aprobación y 
sello de casi toda la comunidad de Estados. Estos son al final, los que asumirán la responsabilidad histórica de ella.

Por otro lado, el concepto de «responsabilidad de proteger» acordado por los Estados plantea algunos problemas normativos que dificultan su desarrollo como norma jurídica ${ }^{29}$. Aparte de que los Estados no han establecido clara y autoritativamente parámetros propios o criterios de legitimidad, tampoco se han referido a la forma en que la responsabilidad del Estado debe ser transferida a la "comunidad internacional» ${ }^{30}$, siendo estos aspectos sustanciales y claves por resolver. En el primer caso, pese a los límites expresados en el Documento Final y a los límites intrínsecos derivados del concepto mismo, el Consejo de Seguridad no está jurídicamente sujeto a tales límites cuando actúa bajo el Capítulo VII, en especial si se trata de una resolución de la Asamblea General. En el segundo caso se plantea concre-

29 Vid. Winkelmann, I., «Responsibility to Protect», The Max Planck EPIL, Oxford University Press, Oxford 2012, 965/972, p. 968 .

30 «Responsibility to protect can -by these standards [set of criteria and the transfer to the Icommunity]- not yet be considered a norm of customary law», Winckelmann, op.cit. (n.29), p. 971; también Amnéus, D., op.cit. (n.26), p. 268ss; Gowlland-Debbas hace mención a problemas de atribución y evidencia pero no se extiende en esto, Gowlland-Debbas, V., "The Security Council as Enforcer of Human Rights", Fassbender, B. (Ed.), Securing Human Rights?, Oxford University Press, Oxford 2011, 36/73, p. 46ss. tamente el problema de la «obligación jurídica», sobre todo de la "comunidad internacional», que acarrearí automáticamente un derecho subjetivo de las poblaciones civiles y una obligación -y no un poder discrecional- del Consejo de Seguridad, lo que restringiría aún más sus facultades. En estas condiciones, el Consejo no estará dispuesto a asumir una responsabilidad de tal envergadura, en especial si se considera que los límites del concepto de la «responsabilidad de proteger" son mayores que los que contempla el Capítulo VII la Carta ${ }^{31}$. Por esta razón, en las resoluciones 1970 y 1973, el Consejo de Seguridad eligió el camino legalmente más seguro y amplio de basarse en los motivos conocidos de "violaciones sistemáticas de derechos humanos» e insertar la «responsabilidad de proteger» en su «canasta» de atribuciones del Capítulo VII, y no al revés, es decir, no adecuó este al concepto de la «responsabilidad de proteger» aceptado por los Estados.

En resumen, el mensaje que sobresale de estas dos cláusulas que contienen la «responsabilidad de proteger» es que la población civil no debe padecer sufrimientos innecesarios y, en las condiciones actuales de la sociedad internacional, será protegida por el sistema de las Naciones Unidas como representante de la comunidad internacional, a defecto del Estado responsable. El Consejo de Seguridad, que es el órgano dotado de poderes jurídicos y materiales para realizar esta tarea tendrá que actuar

31 Vid. Gowlland-Debbas, V., op.cit. (n.30), p. 58. 
M. CeCilia AÑaños • La intervención militar autorizada...

con arreglo al Capítulo VII de la Carta, ampliando el supuesto de «amenaza a la paz» al caso de «no protección de la población civil», teniendo además en consideración los límites arriba indicados solo como una guía de actuación, sin estar jurídicamente obligado por ellos, como lo prueba el caso libio.

\section{AlCANCE DE LA}

\section{AUTORIZACIÓN DEL USO \\ DE LA FUERZA EN LIBIA}

Dado que la intervención militar internacional en el conflicto armado libio llevó al cambio de régimen, nos ocuparemos del alcance de la resolución que la respalda, sobre todo en cuanto a dos cuestiones vitales: la intervención en un conflicto armado y el cambio de régimen. Entonces, responderemos a la pregunta de si las facultades del Consejo de Seguridad se extienden a la intervención en un conflicto armado interno y si las sanciones respaldan el recurso a la guerra con el fin ulterior del cambio de régimen.

En primer lugar, tras considerar que la situación del país constituye una «amenaza a la paz», la resolución 1973 autoriza a cierto número de Estados a tomar "todas las medidas necesarias para "proteger a los civiles y las zonas pobladas por civiles que estén bajo amenaza de ataque» en Libia.». La autorización que se basa en el Capítulo. VII de la Carta, que en su art. 39 permite al Consejo de Seguridad tomar medidas colectivas, incluyendo el uso de la fuerza, o la autorización de esta cuando considere que exista una "amenaza a la paz, quebrantamiento de la paz o acto de agresión» ${ }^{32}$. El problema que encierra este artículo, que data del nacimiento de las Naciones Unidas es la falta de definición de estos tres supuestos, en especial el de «amenaza a la paz», que ha sido empleado casi exclusivamente en la práctica sancionadora de este órgano desde sus inicios. Esta falta de definición otorga tácitamente al Consejo de Seguridad poderes para determinar él mismo en qué momento y bajo qué condiciones una situación determinada o un conflicto interno o internacional constituye una «amenaza

32 Sobre las sanciones de la ONU vid. Pellet, A./Miron, A., "Sanctions", The Max Planck EPIL, Oxford University Press, 2012, vol. IX, p. 1ss.; sobre el régimen legal de las sanciones de la ONU y sus límites vid. Matam Farrall, J., United Nations Sanctions and the Rule of Law, Cambridge University Press, Cambridge 2007; también Matheson, M., Council Unbound: The Growth of UN Decision Making on Confict and Postconflict Issues after the Cold War, United States Institute of Peace, Washington D.C. 2006; Schweigman, D., The Authority of the Security Council under Chapter VII of the UN Charter, Kluwer Law International, The Hague 2001; Tzanakopoulos, A., Disobeying the Security Council, Oxford University Press, Oxford 2011; Gill, T.D., «Legal and Some Political Limitations on the Power of the UN Security Council to Exercise its Enforcement Powers under Chapter VII of the Charter», Netherlands yearbook of International Law, XXVI, 1995, 33/138. Mariño Menéndez, F., Derecho Internacional Público, Ed. Trotta, Madrid 1999, p. P. 503ss. 
a la paz». En otras palabras, la imposibilidad de aprehensión jurídica del concepto de «amenaza a la paz» otorga automáticamente al Consejo de Seguridad los "poderes discrecionales del Capítulo VII», como consecuencia de lo cual ellos terminan siendo tan amplios que pueden llegar a ser ilimitados ${ }^{33}$, convirtiéndose así en un arma sumamente poderosa en manos de potencias hegemónicas que cuentan con derecho de veto en este órgano y que son además capaces de imponer sus propuestas de acción de acuerdo con sus propios intereses. En virtud de estos poderes discrecionales, el Consejo no está sujeto a ningún requisito limitativo en cuanto a los destinatarios de las sanciones, que pueden ser Estados o individuos ${ }^{34}$, ni está limitado en cuanto a los casos que se califiquen como «amenaza a la paz» puesto que no presuponen la existencia de una violación del derecho internacional debido a que la tarea del Consejo no es propiamente velar por el cumplimiento del derecho internacional sino por la paz internacional ${ }^{35}$, que es un concepto más amplio y puede o no suponer un ilícito internacional o no.

33 En este sentido también Gill, T.D., op.cit. (n.32), p. 42.

34 Sobre la interpretración amplia en cuanto a los destinatarios de las sanciones vid. la Opinión Consultiva de la Corte internacional de Justicia en "Ciertos gastos de las Naciones Unidas", I.C.J. Reports 1962, p. 167 .

35 A esto vid. Kelsen, H., The Law of the United Nations, Stevens \& Sons, Londres 1950 p. 730s.
En la práctica, el Consejo ha hecho buen uso de estos "poderes discrecionales», ampliándolos desde 1990 para incluir en el concepto de "amenaza a la paz» casos o situaciones políticas conflictivas de apariencia interna, como disturbios, golpes de Estado, guerras civiles, o conflictos internos relacionados directamente con crisis humanitarias y/o crisis serias de derechos humanos ${ }^{36}$; y solo en segundo lugar ha incluido conflictos propiamente internacionales como el terrorismo internacional o la proliferación de armas nucleares o de destrucción masiva ${ }^{37}$, todo ello inde-

36 A esto vid. Frowein/Krisch, en Simma, B. (Ed.), The Charter of the United Nations, p. 723s., donde los autores observan que el primer conflicto no estrictamente internacional considerado como "amenaza de la paz» es el palestino con la Res. 54 de 1948. Resaltan también las sanciones contra Rodesia del Sur (Res. 232/1966); Sudáfrica (Res.418/1977); Irak (Res. 688/1991); Ex-Yugoslavia (757/1992); Somalia (Res. 733/1992); Haiti (Res. 841/1993); Kosovo (Res.1199/1998); Congo (1341/2001). Sus poderes se extienden prácticamente a la facultad de instaurar tribunales penales internacionales ad-hoc como para la ex-Yugoslavia (Res. 827/1993) y Ruanda (Res. 918/1994, 955/1994).

37 En cuanto al terrorismo internacional, destacan las sanciones contra Libia (Res. 748/1992); Sudán (Res. 1054/1996); Afganistán/Taliban/al-Qaida (Res. 1267/1999); Siria (Res. 1636/2005), y funciones cuasi-legislativas como se ve de las Res 1373 (2001), 687 (1991), 748 (1992). En cuanto a la no proliferación, destacan las sanciones contra Sudáfrica (Res. 418/1977), Irak (Res. 687/1991); Corea del Norte (Res. 1718/ 2006) e Irán (Res. 1737/2006). 
M. Cecilia AÑaños • La intervención militar autorizada...

pendientemente de la capacidad real o dimensión fáctica de tales conflictos para constituir una amenaza a la paz internacional. De acuerdo con esta nueva práctica, los conflictos internos caen entonces dentro del concepto de «amenaza a la paz» ${ }^{38}$. En consecuencia, puede responderse afirmativamente a la pregunta de si el Consejo de Seguridad puede intervenir militarmente en conflictos internos de acuerdo con el Capítulo VII, siempre y cuando considere que ellos involucren crisis humanitarias y/o violaciones graves de los derechos humanos, incluidos crímenes internacionales.

En cuanto a la cuestión de si la resolución 1973 permite expresa o tácitamente el cambio de régimen en Libia, diremos ante todo que el objetivo específico de las medidas colectivas militares autorizadas fue proteger o salvar a la población civil libia, en aplicación de la doctrina de la «responsabilidad de proteger». Pero este objetivo está formulado de manera tan amplia que permite también una interpretación amplia por los responsables de llevarlas a cabo. Así, del tenor literal que autoriza el uso de la fuerza, el objetivo de proteger a «los civiles y las zonas pobladas por civiles» se refiere a los "que estén bajo amenaza de ataque» ( «under threat of attack»), expresión tan vaga que no exige que las

38 Práctica que ha sido confirmada por el Tribunal Penal Internacional para la exYugoslavia (TPIY), The Prosecutor v. Tadi $\rrbracket$, case No. IT-94-1-AR72, Decision on the Defence Motion for Interlocutory Appeal on Jurisdiction del 2 de octubre de 1995, párr. 30. acciones militares respondan a peligros concretos inminentes para la población civil sino simplemente no fija límites a la acción, con lo cual la autorización pasa a ser de carácter preventivo o profiláctico lo que, como se vio riñe abiertamente con el concepto de «responsabilidad de proteger» aceptado por los Estados. El problema más serio es que tal formulación entrega a los ejecutores de las medidas la libre interpretación de lo que entienden por «civiles y zonas pobladas por civiles que estén bajo amenaza de ataque». Así pues, el objetivo de protección de la población civil libia fue interpretado por ellos en sentido abstracto, general e indirecto, para incluir a la población libia en general como potenciales víctimas de "ataques» de su gobierno, independientemente de los actos que este realice. La resolución tampoco define qué medidas militares debieron conducir a la protección de la población civil y autorizó para adoptar las «medidas necesarias», entregando también al criterio de los ejecutores el diseño de su plan militar de "protección a la población civil», que en el caso libio no persiguió concertar treguas de fuego, establecer y proporcionar protección armada a corredores humanitarios, ni zonas desmilitarizadas, evacuar la población de las zonas de combate, etc., sino que libró una guerra ofensiva total contra "presuntos criminales o violadores de los derechos humanos de su población civil y del derecho humanitario», en sentido de la resolución 1973.

Pero ello todavía no nos dice claramente si la resolución 1973 permite el 
cambio de régimen. Indudablemente la resolución no autoriza expresamente el cambio de régimen, pero tampoco lo prohíbe. Es más, contiene varios elementos que llevan a interpretar que lo acepta tácitamente como parte del objetivo de "protección de la población civil» y como consecuencia directa e irremediable de las sanciones mismas ${ }^{39}$. Primero, se encuentra el carácter de sanciones personales o "targeted sanctions", que son a la vez sanciones punibles. Segundo, está el énfasis en la sola responsabilidad de las autoridades libias en circunstancias de que en un conflicto armado causado por una insurrección armada los insurrectos también tienen obligaciones y responsabilidades en la conducción de su lucha armada. Tercero, la sola referencia a la "población civil» y el hecho de que no se mencionen los «insurgentes» revela que el documento no hace diferencia entre ambas categorías de combatientes, distinción que reviste crucial importancia política y jurídica. Cuarto, el hecho de que no se mencione la expresión conflicto armado, siendo que este era un hecho evidente cuando se aprobó la segunda resolución indica que aquí también hay un desequilibrio

39 Algunos autores encuentran el problema de legalidad más a nivel de las acciones de la OTAN y la «coalición internacional» que en la resolución, vid. por ejem. Merkel, R., «Die Intervention der NATO in Libyen. Völkerrechtliche und rechtsphilosophische Anmerkungen zu einem weltpolitischen Trauerspiel», Zeitschrift für internationale Strafrechtsdogmatik, ZIS 10/2011, 771-783, p. 773. en la forma de captar los hechos o un problema de selectividad. Quinto, el apartado 2, que destaca «la necesidad de intensificar los esfuerzos por encontrar una solución a la crisis que responda a las demandas legítimas del pueblo libio», y el hecho de que el documento no mencione en parte alguna la palabra «insurgentes», puede interpretarse en el sentido de que el Consejo de Seguridad identifica las «demandas legítimas del pueblo libio» con las de los «insurgentes", lo que significa que apoya los cambios políticos internos del país, o más claramente el cambio de régimen. Sexto, la celebración y aprobación posterior por el Consejo de Seguridad de los resultados de las operaciones militares, incluyendo los cambios políticos con un nuevo régimen.

\section{LÍMITES DE LAS SANCIONES MILITARES}

Hemos visto anteriormente que el Consejo de Seguridad goza de amplios poderes discrecionales para determinar cuando una situación constituye una «amenaza a la paz» y si hará uso de las sanciones, extendiéndose su libertad a la forma y momento de aplicarlas. El problema que se presentó a partir de los años noventa fue el uso reiterado de tales poderes discrecionales que ha llevado a ampliar el concepto de «amenaza a la paz» más allá de los parámetros de la Carta de las Naciones Unidas. Pero en vez de recurrir a un proceso de reforma de la Carta, como 
ella misma lo establece, se optado por modificarla de forma sigilosa o por la puerta trasera, es decir, via interpretación, o "modificación de facto de la Carta", creando un nuevo derecho que incluso resulta contradictorio con el establecido en la Carta y el derecho internacional. La doctrina iusinternacional preponderante se ha encargado de cimentar esta práctica con la ayuda de técnicas de interpretación que se prestan a este objetivo. Así, haciendo uso de una interpretación teleológica del Art. 39 de la Carta y en virtud de la doctrina de los «poderes implícitos» ${ }^{40}$, confirma los crecientes poderes discrecionales del Consejo de Seguridad para determinar qué actos de un Estado, e incluso de individuos, constituyen una "amenaza» o "quebrantamiento de la paz». ¿Son entonces los poderes del Consejo de Seguridad ilimitados al actuar de acuerdo con el Capítulo. VII de la Carta?

Hay opiniones que responden afirmativamente a la pregunta ${ }^{41}$, sobre todo porque la Carta no establece claramente los límites y debido al carácter eminentemente político de las decisiones que adopta el Consejo con arreglo

$40 \quad$ Vid. Gill, T.D., op.cit. (n.32), p. 69ss.

41 No existen propiamente límites expresos de la Carta a los poderes que el cap. VII otorga al Consejo de Seguridad; de allí que para Kelsen este órgano no está sujeto al derecho con el Art. 39, pudiendo crear nuevo derecho al declarar cualquier conducta de un Estado como una amenaza a la paz, Kelsen, H., op.cit. (n.35), p. 294; a esto vid. Matam Farrall,J., op.cit. (n.32), p. 68ss.; Gill, op.cit. (n.32), p. 64ss. al Capítulo VII, cuyo objetivo es velar por la paz y la seguridad internacionales y no por el cumplimiento del derecho internacional ${ }^{42}$. Tres argumentos que refuerzan aún más esta apreciación son la preeminencia de las obligaciones resultantes de las decisiones del Consejo de Seguridad bajo el Capítulo VII respecto de otros acuerdos internacionales, en virtud del Art. 103 de la Carta $^{43}$; el hecho de que, en virtud del artículo 1 (1) de la Carta, al actuar de acuerdo con el Capítulo VII el Consejo de Seguridad no está sujeto a los principios de justicia y derecho internacional y la presunción general de legalidad de las decisiones del Consejo ${ }^{44}$.

Sin embargo, en su mayoría la doctrina responde negativamente a esta pregunta ${ }^{45}$, sobre todo porque las

42 Kelsen, H., op.cit. (n.35), p. 294.

43 Confirmada por la Corte Internacional de Justicia, en el caso Lockerby «Questions of Interpretation and Application of the 1971 Montreal Convention Arising from the Aerial Incident at Lockerbie» (Libya v. United States), I.C.J. Reports (1992) 114.

44 Se trata, sin embargo, de una validez prima facie, o presunción de que sus actos no son ultra vires, vid. "Certain Expenses of the United Nations», I.C.J. Reports (1962) 151 , at 168; también la Opinión Consultiva sobre Namibia: «Legal Consequences for States of the Continued Presence of South Africa in Namibia (S.W. Africa) Notwithstanding Security Council Resolution 276 (1970)», I.C.J. Reports (1971), p. 16, at pár. 115. También la sentencia del TPIY en Tadic, Prosecutor v. Tadic, de 7 de mayo de 1997, párr. 287.

45 Doehring, K., Völkerrecht, $2^{\circ}$ Ed., 2004, p. 205, quien sostiene que sus decisiones objetivamente ilegales no tienen fuerza obligatoria. A esto vid. Matan Farrall, J., 
decisiones que adopta el Consejo bajo el Capítulo. VII, aunque sean de carácter político y se basen en poderes amplísimos, acarrean consecuencias jurídicas para los destinatarios de las sanciones y terceros ${ }^{46}$, puesto que afectan sus derechos y obligaciones derivados de la Carta y del derecho internacional. Este argumento es respaldado por el reconocimiento expreso-aunque indirecto- de las Naciones Unidas y el Consejo de Seguridad del imperio de la ley, la Carta y el derecho internacional ${ }^{47}$. De

op.cit. (n.37), p. 68ss; también la Corte Internacional de Justicia en «ciertos gastos de las NNUU (párr. 2 Art. 17 Carta)» Opinión Consultiva (1962), opinó que los poderes del Consejo de Seguridad no son ilimitados pero mantuvo la presunción de que actúa intra vires. También la sentencia del TPIY en el caso Tadic, Prosecutor v. Dusko Tadíc, case No IT-94-1-AR72, del 2 de octubre de 1995, párr. 28.

46 Son los demás Estados miembros y no miembros de la ONU, quienes tienen la obligación jurídica de asistir al Consejo de Seguridad, o por lo menos, de no obstaculizar sus operaciones militares con una cooperación pasiva o activa con el Estado o entidad destinario de la sanción, a esto vid. Gill, op.cit. (n.32), p. 60s.

47 El Consejo de Seguridad ha reiterado su "compromiso con la Carta de las Naciones Unidas y el derecho internacional y con un orden internacional basado en el estado de derecho y el derecho internacional, esencial para la coexistencia pacífica y la cooperación entre los Estados para abordar problemas comunes, y contribuir así al mantenimiento de la paz y la seguridad internacionales.», UN Doc. S/PV.6347 del 29 de junio de 2010; menos clara la Res. 1894 (2009) que sólo hace referencia a las obligaciones de los Estados y las partes en confllictos internos. Mas en estos docu- acuerdo con este criterio, puede decirse en primer lugar que los poderes del Consejo de Seguridad no son ilimitados, ante todo porque incluso aceptando la interpretación amplísima o teleológica, que incluye "poderes implícitos", ellos tienen su límite en los propósitos y principios de la Carta de las naciones Unidas, que son también normas válidas del derecho internacional. La norma limitativa principal está en el Art. 24 de la Carta, cuyo apartado 2 nos dice que el Consejo de Seguridad "procederá de acuerdo con los propósitos y principios de las Naciones Unidas». Asimismo, el apartado 1 contiene otras dos restricciones más al expresar que los Estados miembros «confieren al Consejo de Seguridad la responsabilidad primordial de mantener la paz y seguridad internacionales", y que en el desempeño de sus funciones el mismo «actúa a nombre de ellos». Estas restricciones pueden comprenderse mejor desglosándolas de la siguiente manera:

a. En su responsabilidad principal por el mantenimiento de la paz y la seguridad internacionales, el Consejo debe actuar en concordancia con los propósitos y principios de la Carta.

b. En el marco de esta responsabilidad, el Consejo actúa en nombre de los Estados miembros.

c. Los poderes del Consejo derivan de los Estados miembros y no pueden ser más extensos que éstos.

mentos no se encuentra un compromiso directo de obligación a estos parámetros en sus decisiones dentro del cap. VII. 
M. CeCilia AÑaños • La intervención militar autorizada...

Todo examen de la legalidad de las decisiones adoptadas por el Consejo de Seguridad con arreglo al Capítulo VII debe tenier presente estos tres elementos restrictivos que son interdependientes y se sirven uno al otro. Una decisión del Consejo que vaya más allá de los propósitos y principios de la Carta es ultra vires, y por tanto, defectuosa o nula ${ }^{48}$; pero es también ilegal si los contradice, viola o sirve solo para favorecer intereses individuales de los Estados o implica poderes que los Estados no han podido conferir.

Mientras el primer requisito de legalidad -los propósitos y principios de la Carta- requiere un examen especial, al que solo nos referimos sumariamente en este trabajo, el segundo elemento limitativo, el de la actuación en nombre de los Estados, exige que el Consejo de Seguridad, en su función de mantenimiento de lo paz, no actúe en interés propio ni de uno o algunos de los Estados o potencias con derecho a veto, o de sus aliados o clientes, sino en interés de todos los Estados miembros de la Organización, debiendo prevalecer este interés general o común de la «comunidad de Estados» sobre los intereses individuales de cualquier Estado o grupo de Estados ${ }^{49}$. El tercer requisito limitativo, el de los poderes delegados ${ }^{50}$, gira en torno a la palabra „conferir", que se entiende como concesión o

48 Doehring, K., op.cit. (n.45), p. 189.

49 Gill, T.D., op.cit. (n.32), p. 127s.

50 Franck, T., «The 'Powers of Appreciation': Who is the Ultimate Guardian of UN Legality?», AJIL 86 (1992), p. 519 ss. transmisión de poderes que los Estados poseen de acuerdo al derecho internacional y dentro de él, prohibiendo que los poderes del Consejo sobrepasen los poderes soberanos que tendrían los Estados si no existiera este sistema de seguridad colectiva. Ambos elementos exigen a la vez que los Estados miembros estén informados sobre el trabajo realizado en su nombre y no solo sobre sus resultados finales, de manera que se pueda conocer si está actuando en interés de todos los miembros; requisito llamado también de transparencia ${ }^{51}, \mathrm{y}$ no es una facultad sino una obligación del Consejo de Seguridad.

En el caso libio, de la letra de las resoluciones 1970 o 1973 no se desprende que haya existido una transgresión de las obligaciones recién mencionadas porque ellas suponen que se sujetaron a las disposiciones de la Carta. Sin embargo, del análisis de las circunstancias en que se adoptaron se desprende que al avalar y sustentar sanciones ejecutadas por algunos de sus miembros, se violó la obligación de actuar en interés común de los Estados y no se cuestionaron los intereses que tenían los primeros en sacarlas adelante, ni asegurarse de verificar los cargos que las motivaban, ni deliberar sobre la alternativa de otros medios que hubieran llevado a una salida pacífica de la crisis y que

51 Ver Fassbender, B., «The Role of Human Rights in the Decision-making Process of the Security Council», Fassbender (ed.), op.cit. (n.30), 74/97, p. 85, quien hace referencia al carácter secreto de los trabajos del Consejo de Seguridad. 
implicaba sentar a la mesa de negociaciones al gobierno y a los rebeldes, ni reflexionar sobre otras situaciones de poder que giraban en torno al conflicto. El Consejo también rebasó el límite de los poderes delegados al autorizar una guerra para cambiar el régimen político adjunta a la de "protección de civiles». Por último, tampoco se sujetó al principio de transparencia, que se demuestra en la negociabilidad política de ambas resoluciones que habían sido acordadas fuera de las discusiones oficiales del Consejo de Seguridad por los Estados que las promovieron.

\section{LOS PROPÓSITOS Y PRINCIPIOS DE LAS NACIONES UNIDAS}

Dentro de los propósitos enumerados en el Art. 1 de la Carta destaca como fin principal o superior el mantenimiento de la paz mundial y la seguridad internacionales. A este le siguen el fomento de las relaciones de amistad entre los pueblos sobre la base del principio de autodeterminación de los pueblos, y la cooperación internacional en la solución de problemas y en el desarrollo de los derechos humanos. Dentro de los principios que contempla el Art. 2 se destacan, además del principio de la buena fe y del arreglo pacífico de los conflictos, el de la probibición del uso de la fuerza, el de la igualdad soberana de los Estados y el de la prohibición de la intervención. Todos estos propósitos y principios tienen la calidad de normas jurídicas, según la doctrina iusinternacional preponderante, por tanto obligan y otorgan derechos a los Estados, aun siendo discutible el alcance del contenido jurídico de cada uno de ellos ${ }^{52}$. Su configuración y contenido solo pueden determinarse de acuerdo con su evolución a través de la práctica internacional, la jurisprudencia y la doctrina iusinternacional. Entonces, para volver al tema que nos ocupa, de si la Res. 1973 ha transgredido los propósitos y principios de la Carta, observamos que el primer problema cuasi infranqueable es la determinación jurídica de tales conceptos.

Lo anterior se nota de forma especial en el mantenimiento de la paz, que es el fin supremo de las naciones Unidas y se garantiza por el sistema de seguridad colectiva, que a la vez se guía por la prohibición general y absoluta del uso de la fuerza. En un sentido más estricto se lo ha entendido tradicionalmente como el empleo de medidas colectivas con el fin de prevenir o suprimir conflictos armados amplios y en gran escala, capaces de amenazar la estabilidad del sistema internacional prevaleciente. Sin embargo, su indefinición por la Carta deja espacio para la mutación de su contenido de acuerdo con la situación u oportunidad política internacional, que en el sistema de las Naciones Unidas que acarrea forzosamente su ampliación para entender gradual y generosa-

52 Para Doehring es indiscutible su calidad de normas jurídicas aún siendo difícil su interpretación y aplicación, Doehring, K., op.cit. (n.45), p. 82ss. 
M. Cecilia AÑaños • La intervención militar autorizada...

mente otras formas del uso de la fuerza, como las intervenciones humanitarias y actualmente la «responsabilidad de proteger», que precisamente entran en conflicto con la norma central del sistema, de prohibición del uso de la fuerza. Debido a esta falta de definición y a su mutabilidad, el concepto de mantenimiento de la paz parece tolerar cada vez más el uso de medios bélicos en vez de pacíficos, de modo que ese es el estado actual del sistema de seguridad colectiva de las naciones Unidas. De acuerdo con ello, no es posible reconocer una contradicción directa de la Resolución. 1973 con este propósito.

El principio de la prohibición absoluta del uso de la fuerza, norma perentoria o de ius cogens y a la vez norma básica del sistema de seguridad colectiva de las Naciones Unidas tampoco se destaca por su precisión, por mucho que fuera aclarada por la Declaración de Principios del Derecho Internacional ${ }^{53}$. Sin embargo, de la Resolución 1973 no se puede deducir directamente una transgresión de esta norma, debido a que el Capítulo VII la permite como excepción. La resolución solo pierde el sustento legal del capítulo VII en el caso de que sea evidente que el supuesto de

53 UN Doc. UN/A/Res. 2625 (XXV), 24 de octubre de 1970. Actos incluidos en esta prohibición son la guerra de agresión y el uso de la propaganda en favor de ella, el uso o amenaza de la fuerza como medio de resolver controversias internacionales, el uso o amenaza de la fuerza que prive del derecho de la libre determinación o la libertad e independencia de los pueblos, y la inviolabilidad del territorio estatal. «amenaza a la paz» se apoya en hechos falsos o no existentes y la autorización de las medidas militares se convierte en un uso ilegítimo de la fuerza o guerra de agresión. No obstante, un examen más acabado de la legalidad de las sanciones exige indagar también si antes de ellas y en relación directa con ellas hubo actos de los Estados ejecutantes -la Coalición Internacional y la OTAN en nuestro caso- reñidos con la prohibición del uso de la fuerza del Art. 2 (4) de la Carta, a fin de comprobar la integridad de las sanciones respecto de la norma y el comportamiento diferenciado que debe existir entre los Estados que las promueven y ejecutan y el Consejo de Seguridad. Así pues, la prohibición del uso de la fuerza incluye la obligación de todo Estado de «abstenerse de organizar, instigar, ayudar o participar en actos de guerra civil [...] en otro Estado. $\left[\ldots .{ }^{54}\right.$. En el caso libio no puede demostrarse que antes de que comenzara la crisis interna los Estados que aplicaron las sanciones hayan tenido un plan para la desestabilización del Estado libio y el cambio de régimen. Si hubiese existido habría sido equivalente a un crimen de agresión prohibido por la Carta y el derecho internacional, sobre todo por el carácter pérfido de la preparación conspirativa de la guerra ${ }^{55}$.

54 UN Doc. UN/A/Res. 2625 (XXV), 24 de octubre de 1970.

55 Ello si se comprueba el plan de desestabilización con el empleo de «operaciones encubiertas» y "operaciones negras», y con la participación de los servicios secretos de países extranjeros. La información de que la „revuelta de Bengasi« fue pla- 
El principio de igualdad soberana de los Estados, formulado en el Art. 2(1) de la Carta, está estrechamente vinculado con el concepto de soberanía, y fue también precisado en la Declaración sobre los Principios del Derecho Internacional ${ }^{56}$, siendo un principio fundacional del Estado que incluye su derecho de existencia y preservación. De ahí que se sirva de otros, como los de la prohibición de la intervención y el derecho de la autodeterminación de los pueblos. Asimismo, otro principio que deriva de él es la prohibición de la $\operatorname{arbitrariedad}^{57}$ o requisito de objetividad, que exige un comportamiento lógico y justo entre los Estados y entre una organización internacional y estos; que en el caso particular del Consejo de Seguridad debe demostrarse en su trato igual hacia los Estados miembros $\mathrm{y}$ en las decisiones y/o sanciones que impone sobre ellos. La autorización de una intervención militar con el objetivo último de deponer a un gobierno debido a que constituye un obstáculo contra planes políticos hegemónicos en la zona geoestratégica del Mar Mediterráneo, es un fin arbitrario reñido con

neada por desertores libios y los servicios secretos franceses en Francia desde noviembre de 2010, vid. Red Voltaire http:// www.voltairenet.org/Francia-estaba-preparando-el, es fragmentada pero no descartable, y necesitará de su comprobación por investigaciones posteriores.

56 UN Doc. A/RES 2625 (XXV), 24 de octubre de 1970 . Vid. Ipsen, K., Völkerrecht, $3^{\circ}$ Ed., CH Beck, München 1990, p. 336. 57 'En este sentido Lorinser, B., Bindende Resolutionen des Sicherheitsrates, Nomos, Baden-Baden 1996, p. 54. este principio ${ }^{58}$. Mas como se dijo, del contenido de la Resolución 1973 no se puede desprender directamente su intención de conducir a este fin.

El principio de no intervención, que establece el Art. 2(7) de la Carta encierra la obligación de no intervenir en los asuntos de jurisdicción interna de los Estados mediante el uso o amenaza de la coerción ${ }^{59}$, y es una norma que sigue teniendo valide $z^{60}$ pese a su aparente derogación tácita. Su suspensión por el Capítulo VII de la Carta no impide extender el examen de legalidad de las sanciones a actos anteriores directamente relacionados con ellos. Entonces, un juicio cabal de las sanciones contra Libia obliga examinar la conducta de los Estados involucrados en el conflicto y de las Naciones Unidas antes de ellas para determinar si se ajustaron a esta norma y descartar posibles vicios consistentes en legitimar una violación flagrante de la Carta y, por tanto, una violación del derecho internacional. Una primera revisión de los hechos previos a las sanciones contra Libia revela que los Estados que aplicaron las sanciones y las naciones Unidas realizaron diversos actos de intervención prohibidos. La prohibición comprende ante todo "organizar, apoyar,

58 En este sentido también Lorinser, op.cit. (n.57), p. 56.

59 Kunig, Ph., "Intervention, Prohibition of», The Max Planck EPIL, vol. VI, Oxford Universitiy press, Oxford, 2012, p. 293.

60 «Armed Activities on the Territory of the Congo: (Democratic Republic of the Congo v. Uganda)», I.C.J. Reports 2005, p. 168 , párr. $163 \mathrm{~s}$. 
M. CeCilia AÑaños • La intervención militar autorizada...

formentar, financiar, instigar o tolerar actividades armadas, subversivas o terroristas encaminadas a cambiar por la violencia el régimen de otro Estado $y$ de intervenir en una guerra civil de otro Estado» ${ }^{61}$. Aunque no se puede demostrar la intervención directa de Estados como Francia y Qatar en la planificación y organización de estas actividades, sí puede demostrarse un apoyo consecuente, gradual y sistemático a los rebeldes libios desde los inicios de la crisis con la «revuelta de Bengasi», que consistió en presentar el conflicto libio a nivel internacional como un caso de «crimen internacional» y no como un conflicto armado protagonizado por insurrectos organizados militar y políticamente para tomar el poder. Cabe recordar que la insurrección armada genera un estado de emergencia en el cual el gobierno puede actuar contra los insurrectos y suspender ciertas garantías de derechos humanos, situación que constituye en primer término asunto interno de un Estado ${ }^{62}$, y que el derecho internacional prohíbe la intervención extranjera en favor de los insurrectos ${ }^{63}$ y solo se justifica si es evi-

61 Declaración de Principios del Derecho Internacional UN Doc. A/RES 2625 (XXV), 24 de octubre de 1970.

62 Se trata de una acción de preservación en sentido de un estado de emergencia (Notstand), Doehring, K., op.cit. (n.45), p. 331. Partsch, K.-J., «Self-Preservation», EPIL 2000, T. 4, p. 380.

63 Doehring, K., op.cit. (n.45), p. 202, p. 276.; Kunig, Ph., op.cit. (n.59), p.295. Para Akehurst la intervención extranjera en una guerra civil puede considerarse como una subversión y tiene la calidad de dente que el gobierno viola gravemente derechos humanos fundamentales o comete sistemáticamente crímenes de lesa humanidad. En el caso de Libia, el problema radica en la evidencia de tales crímenes. La intervención no se prohíbe únicamente si las acusaciones son probadamente veraces, de lo contrario existe una violación flagrante de la norma en la forma de intervención subversiva o propaganda de guerra. Asimismo, se observa una intervención prohibida por el derecho internacional en el reconocimiento prematuro y de facto del CNT por las naciones Finidas como gobierno libio legítimo y representante del Estado libio antes de que se aprobaran las sanciones.

El derecho de autodeterminación, formulado en el Art. 1 (2) de la Carta, que tiene rango de norma de ius cogens, obliga íntegramente al Consejo de Seguridad en sus actos de mantenimiento de la paz al no ser afectada por el Capítulo VII de la Carta. La insurrección armada que en si es un acto ilegal que se mueve dentro de la esfera interna de ese Estado es una manifestación de la autonomía del pueblo, si y solo si es llevada a cabo por los nacionales y ciudadanos de ese Estado en determinadas condiciones, sobre todo cuando sus derechos se nie-

\footnotetext{
"ataque armado indirecto» si los extranjeros ayudan a los rebeldes en su insurrección, Akehurst, M., "Civil War», EPIL 1982, T. 3, p. 91s. Confirmada por la Corte Internacional de Justicia en el fallo "Armed Activities on the Territory of the Congo: (Democratic Republic of the Congo v. Uganda), I.C.J. Reports 2005, p. 168, párr. 163,164.
} 
gan en forma sistemática y dentro del Estado existen previamente demandas concretas de ellos por la vía legal y pacífica ${ }^{64}$. En cambio, la lucha armada de un grupo determinado del pueblo con el fin de deponer a su gobierno - que en última instancia es también una expresión de autonomía- no alcanza la calidad del derecho de autodeterminación de los pueblos, protegido por el derecho internacional, por lo cual no puede beneficiarse de él y corresponde entonces a la esfera interna del Estado. Éste fue el caso de los insurrectos libios bajo el nombre de CNT, conglomerado formado por distintos grupos étnicos, sociales y políticos para tomar el poder político libio y del cual no se conoce demandas previas de mayores derechos o autonomía, ni de lucha contra opresión alguna. Entonces, la ayuda extranjera a los insurrectos libios no se otorgó a un movimiento de liberación para que ejerciera el derecho de autodeterminación sino para que cambiara de gobierno. La violación del derecho de autodeterminación del pueblo libio por los Estados extranjeros que intervinieron en favor de los rebeldes solo procede si la intervención fue planificada anticipadamente desde afuera, con actos

64 El derecho de autodeterminación está ligado con demandas de más derechos y autonomía de un grupo determinado. Pero para el uso ofensivo de este derecho y su protección por el derecho internacional, se exige además que este grupo o minoría sufra opresión sistemática por el gobierno y respete el principio de proporcionalidad que significa recurrir primero a los medios legales y pacíficos. positivos de organización, financiación, adiestramiento y mantenimiento de la oposición nacional y preparación de la lucha armada, siendo estos movimientos de «oposición» guiados únicamente por ese plan, fenómeno conocido como "cambio de régimen». De acuerdo con la información disponible sobre el caso libio, el fenómeno se dio en la forma especial de "cambio encubierto de régimen", debido a que fue planificado y realizado por los nacionales del país. En cuanto a las Naciones Unidas, resulta aún más difícil determinar si hubo transgresión del derecho de autodeterminación del pueblo libio ya que los rebeldes se presentaron ante la sociedad internacional como representantes del pueblo libio.

Los derechos humanos mencionados en el Art. 1(3) de la Carta han adquirido excepcional valor en las relaciones internacionales y en el derecho internacional, al punto que la segunda mitad del siglo XX y comienzos del siglo XXI se caracterizan como la «época del derecho internacional de los derechos humanos». Algunas de sus normas tienen el rango de ius cogens con obligaciones erga omnes y son un elemento fundamental del mantenimiento de la paz en el marco de las naciones Unidas. De acuerdo con ello, los Estados están obligados a promover y respetar sus normas fundamentales ${ }^{65}$, y en casos de conflictos

65 Se trata de normas imperativas o de ius cogens con obligación erga omnes. Dentro de esta categoría se encuentran el derecho a la vida, a la integridad corporal, a la protección contra un tratamiento inhuma- 
M. Cecilia AÑaños • La intervención militar autorizada...

armados internos, las contenidas en el Art. 3 común de los cuatro Convenios de Ginebra ${ }^{66}$. Aunque no son parte en los pactos y convenios internacionales de derechos humanos, las Naciones Unidas están obligadas jurídicamente a observarlos, no solo por tratarse de normas fundamentales, y por tanto irrenunciables, sino porque además de que estas forman parte de los propósitos de la Organización, las han promovido y reforzado constantemente y las han situado en el más alto nivel normati$\mathrm{vo}^{67}$. En consecuencia, las decisiones y

no, cuando son afectadas arbitrariamente, a esto vid. Doehring, K., op.cit. (n. 45), p. 434; otros derechos dentro de esta categoría son el derecho a la no discriminación y el derecho a un juicio justo.

66 Dentro de ellas están la prohibición del tratamiento inhumano y discriminatorio de no combatientes, la prohibición de la violencia, tortura, tratamiento indigno y degradante, la privación arbitraria de la vida incluida la ejecución extralegal. A esto vid. también el fallo de la Corte Internacional de Justicia sobre Nicaragua, I.C.J. Reports 1986, párr.218.

67 La sujeción del Consejo de Seguridad a los derechos humanos fue confirmada por la Corte Internacional de Justicia, en su Opinión Consultiva sobre Namibia. También ha sido reconocida por la propia ONU aunque sólo en cuanto al impacto de sus medidas pero no en cuanto a la sanción misma; así el ex Secretario General, Kofi Annan, sostuvo que «El sistema de las Naciones Unidas debe reafirmar su determinación de respetar, cumplir y aplicar el derecho internacional, los derechos humanos fundamentales y las normas procesales básicas, UN Doc. A/59/2005 (21.03.2005), párr. 113. A esto vid. Fassbender, B., op.cit. (n.57), p. 79s. actuaciones del Consejo con arreglo al Capítulo VII no deben transgredirlas.

Las sanciones personales o «targeted sanctions» de las resoluciones $1970 \mathrm{y}$ 1973 afectgaron masivamente derechos humanos fundamentales como la libertad de movimiento, el derecho a un juicio justo, el derecho de propiedad, etc., por no mencionar la autorización del empleo de las «medidas necesarias» que dio un cheque en blanco para intervenir en otros derechos, como el derecho a la vida, la dignidad personal, la integridad corporal, la salud, etc. Su justificación depende ante todo del motivo legítimo, dado en la veracidad de los actos que se reprochan, o por lo menos de su verosimilitud, y de la necesidad de las medidas para proteger a la población civil libia. A juzgar por su plausibilidad y por las pruebas disponibles, en la crisis libia no parecen haberse justificado estas intervenciones en los derechos humanos de los destinatarios de las sanciones. Asimismo, un buen número de ellas fue de carácter punitivo y por tanto desproporcionadas respecto del fin de protección de la población civil; puesto que ella habría podido lograrse mediante otras medidas más coherentes y apropiadas e incluso, más eficaces, como acuerdos de tregua y desmilitarización, así como el envío de observadores internacionales y de una comisión de mediación con poderes para negociar un acuerdo de paz que incluyera la transición pacífica hacia un gobierno democrático sin capitulación, y que no quitara dignidad al gobierno y sus familias. Es incomprensible que 
ambas resoluciones no mencionaran la necesidad de establecer un cese de fuego, la negociación de treguas o la suspensión de las hostilidades por ambas partes, elemento importante y hasta imprescindible para la protección de la población civil libia. Igualmente incomprensible es que no mencionaran a los «insurgentes», soslayando la posibilidad de que violaran derechos humanos fundamentales y normas del derecho humanitario, como lo hicieron con miembros fieles al gobierno y sus familias, y en especial la ejecución extrajudicial del líder del gobierno, Gadafi, en circunstancias degradantes e inhumanas, y de miembros de su familia, las que han quedado impunes. La simple amonestación por parte del Consejo de Seguridad y las naciones Unidas sin traer a la justicia a los responsables de este y otros crímenes, como se ha hecho con el gobierno libio de Gadafi, no solo implica un comportamiento discriminatorio y selectivo, ultrajante al sentido de justicia, sino también una forma de complicidad con tales crímenes, pues precisamente estos también incluyeron graves violaciones de derechos humanos fundamentales que debieron caer en la competencia de la Corte Penal Internacional y ser investigados por ella. La inhibición de la Corte Penal Internacional para abrir una investigación y traer a la justicia a sus responsables con la excusa de que el gobierno libio actual se encargará de ello es decepcionante y le resta legitimidad a una institución llamada a actuar de acuerdo con los principios de independencia e imparcialidad judicial.

\section{CONCLUSIÓN Y \\ REFLEXIONES FINALES}

Lo expuesto revelase que los poderes del Consejo de Seguridad bajo el Capítulo VII no son ilimitados debido a que están sujetos a las restricciones del Art. 24 de la Carta, que exigen ante todo que no se violen los propósitos y principios de la Organización. Sin embargo, esta norma se torna inservible o ineficaz debido a la falta de definición y variabilidad de estos propósitos y principios, lo que hace aún más difícil todo control material de las actuaciones del Consejo de acuerdo con este Capítulo, con mayor razón porque no existe mecanismo alguno de control autoritativo posterior ni una instancia internacional independiente e imparcial de supervisión o revisión. De acuerdo con este orden, las sanciones evidentemente ilegales no corren peligro de ser nulas y el Consejo no estará obligado a rendir cuenta de sus actuaciones ilegales, de tal modo que hay impunidad frente a los cuantiosos daños humanos y materiales resultantes de un régimen de sanciones ilegal e injusto. De allí que se tenga que admitir que en la práctica los poderes del Consejo son ilimitados, por mucho que jurídicamente tengan claras limitaciones. Se trata aquí de un problema grave del sistema de seguridad colectiva de las Naciones Unidas, porque la constante auto-extensión de 
M. Cecilia AÑaños • La intervención militar autorizada...

los poderes discrecionales del Consejo y la falta de control institucional de ellos no solo afecta negativamente toda restricción jurídica a su respecto sino esta se convierte también en una arma poderosa del poder cuya legalidad y legitimidad pende del solo hilo del Capítulo VII de la Carta.

$\mathrm{El}$ régimen de sanciones de las $\mathrm{Na}$ ciones Unidas, que en la crisis libia se presenta como el más efectivo y aceptado de su historia, estuvo impregnado del concepto de la «responsabilidad de proteger»,y se caracterizó por contener sanciones individuales («targeted sanctions») y punitivas, con un destinatario definido, el régimen de gobierno libio, y ser de naturaleza preventiva o profiláctica de protección a la población civil, cuya base legal no se encuentra propiamente en la «responsabilidad de proteger» sino en los poderes amplios del Capítulo VII de la Carta.

La revisión de las limitaciones intrínsecas del concepto de la «responsabilidad de proteger» permite concluir que la intervención internacional contra Libia no fue auténticamente para proteger a la población civil, y por tanto, no sirve como precedente de la doctrina. Una serie de elementos de esta práctica apuntan a una intervención para cambiar el régimen político. Por otro lado, las dos resoluciones adolecen de vicios de validez tanto en el proceso deliberativo como en su legitimación material, en vista de que al gobierno libio se le negó injustificadamente su derecho a participar en las deliberaciones y ser oído, en que se otorgó reconocimiento dudoso y prematuro a los rebeldes y se transgredió el Art. 24 de la Carta debido a que no pudo percibirse que el Consejo hubiese actuado en nombre de los Estados en su conjunto y a que rebasó sus poderes conferidos al autorizar el uso de la fuerza con el fin último de cambiar el régimen. En cuanto a los propósitos y principios de la Carta, hay discordancias y fuertes dudas de su respeto, en especial respecto de los derechos de igualdad soberana, de autodeterminación de los pueblos y de los derechos humanos, no pudiendo ofrecerse una conclusión definitiva debido a que actualmente no pueden demostrarse los hechos que realmente dieron lugar a las sanciones y a la relativa flexibilidad de estos propósitos y principios. Asimismo, se ha observado también que en Libia las sanciones legitimaron intervenciones anteriores prohibidas de los Estados y de las $\mathrm{Na}$ ciones Unidas y queda por resolver si también legitimaron actos de agresión anteriores de los Estados que las promovieron. Otras incongruencias serias son su carácter individual y/o punitivo y profiláctico o preventivo, que riñe con el principio de proporcionalidad.

Entrando ya al nivel político, el Consejo de Seguridad ha abierto el camino a una nueva era de intervenciones militares que llevarán el sello de la «responsabilidad de proteger», que se acompañarán del cambio de régimen en el país afectado, lo que aumentará aún más el grado de tolerancia al recurso a la guerra o ius ad bellum, menoscabando con ello los mismos propósitos 
y principios de las Naciones Unidas y del derecho internacional público que le sirven de límites. Las Naciones Unidas, como organización universal de seguridad colectiva ha desempeñado en esta intervención el infortunado papel de ser el «botón automático» de la voluntad de determinados Estados, y reducirse a ser mero portavoz suyo, ignorando su deber de representar los intereses de los Estados miembros de las Naciones Unidas en su conjunto y de trabajar por el bien común de la paz. Esta última actuación entierra definitivamente el sueño de que el uso colectivo de la fuerza sería menos cuestionable que su uso unilateral desde el punto de vista moral y jurídico. Por el contrario, el régimen de sanciones de las naciones Unidas se ha convertido en un mecanismo despiadado contra regímenes de facto o democráticos «rebeldes» al orden internacional establecido o el statu quo de tendencias hegemónicas y jerárquicas; lo que también nos demuestra que el sistema de seguridad colectiva existente no funciona como promotor de la paz internacional sino como agencia o vehículo de fuerzas hegemónicas, la que es más despiadada cuando se eleva al exponente 193, que prohibe a los demás Estados ser neutrales cuando tienen serias dudas de la legitimidad de las sanciones. Los daños son incalculables para los destinatarios y el país afectado, y solo pueden medirse en su dimensión histórica; convirtiéndose tal hecho en una injusticia insoportable si se prueba que el motivo de las sanciones fue escenificado o pretextado. Asimismo, este sistema de seguridad colectiva no solo es estéril frente a intervenciones extranjeras hegemónicas prohibidas, sino que hace parte de ellas con el poder concedido de buena fe por los Estados. Estas intervenciones secretas o encubiertas se están practicando con éxito en diferentes lugares del mundo y no solo tienen la gran ventaja de ser difíciles de verificar y contar con la supuesta justificación del ejercicio de la autonomía del pueblo, sino además de ser mucho más económicas, porque implican costos mucho más bajos que la intervención directa para el cambio de régimen, como ocurrió en Granada en 1983 y Panamá en 1989, que no fueron más que golpes de Estado operados desde afuera.

En la crisis Libia, el papel de las organizaciones regionales, como la Liga Árabe, la Organización para la Conferencia Islámica y la Unión Africana tampoco puede considerarse positiva, debido a su actuación inicial precipitada y condenatoria, lo que demuestra el fracaso de los sistemas regionales de seguridad colectiva, en especial el africano, en sus objetivos de «lograr una mayor unidad y solidaridad entre los países africanos» y de «defender su soberanía, integridad territorial e independencia». El manto protector de la UA frente a cualquier tipo de incursiones hegemónicas extranjeras tiene un enorme hueco que no sólo hace a esta organización en inservible para estos fines, sino que además ella misma parece contribuir más al menoscabo que a la protección 
M. CeCilia AÑaños • La intervención militar autorizada...

de los intereses de los Estados que la conforman. Esta absurda y lamentable situación es aún más intensa y notoria en la Liga Árabe y la Organización para la Conferencia Islámica.

Por último, es de notar que en su forma actual el sistema de seguridad colectiva de las Naciones Unidas está transformando el sistema internacional en un orden gradual y jerarquizado, y con ello está eliminando la estructura de coordinación de los Estados a la vez adecuando el derecho internacional a este orden. La «responsabilidad de proteger» es el mejor ejemplo de estas tendencias de «individualización» del derecho internacional hacia un derecho aún más individualista, más liberal y más autoritario, que terminará imponiéndose en vista de la aquiescencia de los demás Estados miembros de las $\mathrm{Na}$ ciones Unidas que tienen menos poder, cuyos intereses de corto plazo parecen concentrarse en buscar el «enganche» en este orden político jerarquizante, conformándose finalmente con estos desarrollos. Estos cambios serían inobjetables si significasen un progreso moral de la humanidad y del derecho internacional. Por desgracia, constituyen más bien un desarrollo anómalo ${ }^{68} \mathrm{O}$ un retroceso moral a épocas que se creyeron superadas en la historia, porque destruyen el respeto entre los Estados, crean nuevas formas de discriminación entre ellos, anteponen el bien individual all bien común y regeneran relaciones de dominio o de corte colonial entre

68 Merkel, R., op.cit. (n.44), p. 775. ellos. ¡No se avisan buenos vientos ni para la sociedad internacional ni para el derecho internacional!

\section{Bibliografía}

Akehurst, M.,(1982) «Civil War», Encyclopedia of Public International Law, Amsterdam,Nord-Holland P.C.,

Amnéus, D., (2008) Responsibility to Protect by Military Means, Estocolmo, Stockholm University., .

Añaños Meza, M. C.,(2009) «La 'responsabilidad de proteger' en Naciones Unidas y la doctrina de la «responsabilidad de proteger», INSCI Discussion Papers No 21, 2009; Anuario Mexicano de Derecho Internacional No $10 .$.

Añaños Meza, M. C.,(2012), La «Responsabilidad de proteger» $y$ la intervención de la ONU en Libia, EAE.

Birkhäuser, N.,(2007), Sanktionen des Sicherheitsrats der Vereinten Nationen gegen Individuen, Berna,Peter Lang..

Doehring, K.,(2004), Völkerrecht, $2^{\circ}$ Ed., Heidelberg, Müller..

Fassbender, B.,(2006) Targeted Sanctions and Due Process, Berlin, HU..

Franck, T.,(1992), «The 'Powers of Appreciation': Who is the Ultimate Guardian of UN Legality?», AJIL 86 (1992), 519/523.

Gill, T.D.,(1995), «Legal and Some Political Limitations on the Power of the UN Security Council to Exercise its Enforcement Powers under Chapter VII of the Charter", Netherlands Yearbook of International Law, XXVI, 1995, 33/138.

Gowlland-Debbas, V., (2011), «The Security Council as Enforcer of Human Rights», en Fassbender, B. (Ed.), Securing Human Rights?, Oxford, Oxford University Press..

Ipsen, K.,(1990), Völkerrecht, $3^{\circ}$ Ed., Munich,CH Beck..

Kelsen, H. (1950), The Law of the United Nations, Londres, Stevens \& Sons..

Kunig, Ph.,(2012), «Intervention, Prohibition of», The Max Planck Encyclopedia of 
Public International Law, vol. VI, Oxford, Oxford Universitiy Press.

Kuyper, P.J.(1978), The Implementation of International Sanctions, Amsterdam, Univ. Diss..

Lorinser, B., (1996), Bindende Resolutionen des Sicherheitsrates, Baden-Baden , Nomos..

Mariño Menéndez, F.,(1999), Derecho Internacional Público, Madrid, Ed. Trotta..

Matam Farrall, J.,(2007), United Nations Sanctions and the Rule of Law, Cambridge, Cambridge University Press..

Matheson, M., (2006), Council Unbound: The Growth of UN Decision Making on Confict and Postconflict Issues after the Cold War, Washington, D:C:, United States Institute of Peace..

Merkel, R., "Die Intervention der NATO in Libyen. Völkerrechtliche und rechtsphilosophische Anmerkungen zu einem weltpolitischen Trauerspiel», Zeitschrift für internationale Strafrechtsdogmatik, ZIS 10/2011, 771-783.

Partsch, K.-J.,(2000), "Self-Preservation», Encyclopedia of Public International Law, Amsterdam, Norh-Holland, T. 4, Q-Z, 380/383.

Pellet, A./Miron, A.,(2012) «Sanctions», The Max Planck Encyclopedia of Public International Law, vol. VI, Oxford, Oxford Universitiy Press, vol. IX, 1/15
Randelzhofer, A., (2000), "Use of Force», Encyclopedia of Public International Law, Amsterdam, North-Holland, T. 4, Q-Z, 2000, 1246/1258.

Schweigman, D.,(2001), The Authority of the Security Council under Chapter VII of the UN Charter, La Hayha, Kluwer Law International.

Simma, B. (Ed.),(2002), The Charter of the United Nations, Oxford, Oxford University Press..

Tzanakopoulos, A.,(2011), Disobeying the Security Council, Oxford, Oxford University Press..

Willis, G.L.,(2011), «Security Council Targeted Sanctions, Due Process and the 1267 Ombudsperson", Georgetown Journal of International Law, Vol. 42, 673-745.

Winkelmann, I., (2012) «Responsibility to Protect", The Max Planck Encyclopedia of Public International Law, Oxford, Oxford University Press..

Wolf-Zimper, G.,(2008), Zielgerichtete Sanktionen des Sicherheitsrates der VN und effektiver Rechtsschutz, Frankfurt a.M., Univ. Diss., Lang.. 